\title{
Throttling Impacts on Hall Thruster Performance, Erosion, and Qualification for NASA Science Missions
}

\author{
John W. Dankanich ${ }^{1}$ \\ Gray Research, Inc., Huntsville, AL, 35806
}

And

Amado DeHoyos ${ }^{2}$

Space Exploration Technologies, McGregor, TX, 76638

\begin{abstract}
With the SMART-1, Department of Defense, and commercial industry successes in Hall thruster technologies, NASA has started considering Hall thrusters for science missions. The recent Discovery proposals included a Hall thruster science mission and the In-Space Propulsion Project is investing in Hall thruster technologies. As the confidence in Hall thrusters improve, ambitious multi-thruster missions are being considered. Science missions often require large throttling ranges due to the $1 / \mathrm{r}^{2}$ power drop-off from the sun. Deep throttling of Hall thrusters will impact the overall system performance. Also, Hall thrusters can be throttled with both current and voltage, impacting erosion rates and performance. Last, electric propulsion thruster lifetime qualification has previously been conducted with long duration full power tests. Full power tests may not be appropriate for NASA science missions, and a combination of lifetime testing at various power levels with sufficient analysis is recommended. Analyses of various science missions and throttling schemes using the Aerojet BPT-4000 and NASA 103M HiVHAC thruster are presented.
\end{abstract}

\section{Introduction}

M ission analyses have been conducted and published for various potential NASA missions to compare the performance of thruster technologies. Some of the assumptions used in mission studies are that the lifetime is limited by the throughput capability of a thruster at full power and that multiple thrusters will always throttle consecutively. In some cases, the lifetime of a thruster for an actual mission profile is dramatically different than that of full power operation.

\section{Thruster Background}

Thrusters used for this study included the Aerojet BPT-4000 and the NASA 103M High Voltage Hall Accelerator (HiVHAC) thruster. The two thrusters were chosen because they are Hall thrusters similar in maximum power level and both have been previously considered for NASA science missions. Heritage commercial Hall thrusters typically do not have sufficient throughput capability required for primary propulsion on a NASA science mission. Both the BPT-4000 and HiVHAC thrusters represent significant improvements over previous Hall thruster lifetimes, but with different approaches to increase throughput capability. Thruster throttle tables used in this study are representative only; both thrusters can operate outside of the limited throttle regions used in this analysis. Figure and Table 1 show a comparison of the two Hall thrusters.

\section{A. HiVHAC}

Under an In-Space Propulsion (ISP) Cycle-2 NASA Research Announcement, the High Voltage Hall Accelerator (HiVHAC) was proposed and awarded to the NASA Glenn Research Center (GRC). GRC

\footnotetext{
${ }^{1}$ Systems Engineer, NASA's In-Space Propulsion Technology Project, John.Dankanich@nasa.gov, Member AIAA.

${ }^{2}$ Propulsion Test Engineer, adehoyos@spacex.com.
} 
teamed with Aerojet, JPL and the University of Michigan to develop a 6-kWe to 8-kWe Hall thruster with moderate Isp for Flagship class missions. After the focus of ISP shifted from large missions to smaller Discovery and New Frontiers missions, the HiVHAC program was realigned to develop a lower power HiVHAC thruster operating at approximately $3 \mathrm{~kW}$ with the goal of increasing low power performance and reducing the cost for Discovery-class electric propulsion missions. As shown in Table 1, the HiVHAC thruster has a large throttle range as well as a large specific impulse range.

With the end of Cycle-2 funding, the HiVHAC program is being continued as a high-risk/high-payoff inhouse thruster development effort at GRC. The goal is the development of a low cost 3.75-kWe thruster with an operational lifetime exceeding than 30,000 hours through the use of an in-situ channel replacement technique. The HiVHAC is undergoing substantial wear testing throughout FY07 to validate this in-situ life extension process.

\section{B. BPT-4000}

Aerojet completed qualification of the BPT-4000 Hall thruster in 2006. The BPT-4000, a $4.5 \mathrm{~kW}$ multimode Hall thruster, is part of an Aerojet and Lockheed Martin Space Systems Company activity to develop a Hall Ion Propulsion System (IPS) for use on geosynchronous satellites. The BPT-4000 thruster is designed to operate between $3-\mathrm{kWe}$ and $4.5-\mathrm{kWe}$ at discharge voltages between 300 volts and 400 volts. The thruster will be able to operate at lower voltage and higher thrust-to-power for orbit raising maneuvers, and at higher voltage, higher specific impulse during station keeping. ${ }^{1}$

In 2006, the In-Space Propulsion Office funded an extension of the Aerojet BPT-4000 life test to demonstrate a higher throughput capability and to assess the performance of the thruster at low power operation. ${ }^{2}$ Total qualification life testing processed approximately $272 \mathrm{~kg}$ of xenon propellant, for a flight operational throughput capability of $181 \mathrm{~kg} .{ }^{3}$ Based on the results of the recently completed life test, it is predicted that the thruster will have a mission throughput capability greater than $285 \mathrm{~kg}$ of propellant.

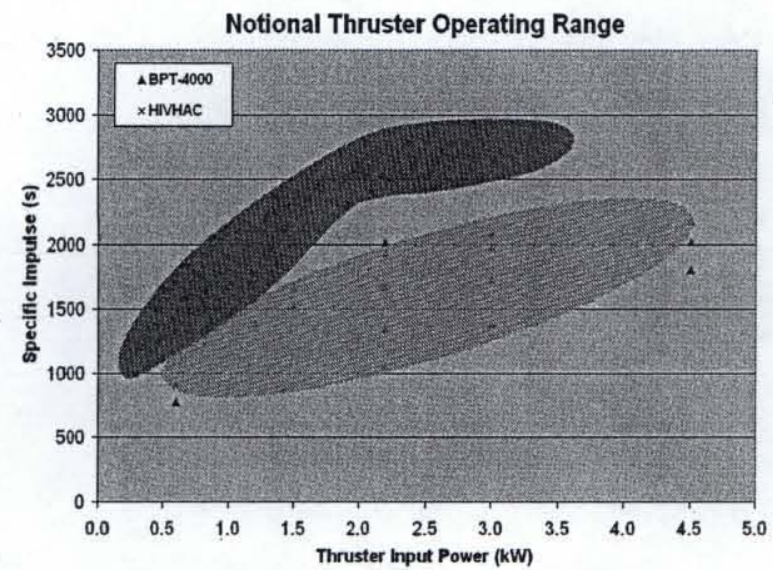

Table 1: Hall thruster metric comparison.

Figure 1: Notional Performance Ranges for BPT-4000 and HiVHAC.

\begin{tabular}{|l|c|c|}
\cline { 2 - 3 } \multicolumn{1}{c|}{} & HiVHAC & BPT-4000 \\
\hline Max. Input Power (kW) & 3.6 & 4.5 \\
\hline Throttle Range & $12: 1$ & $4: 1$ \\
\hline Specific Impulse (s) & 2750 & 1983 \\
\hline Thrust (mN) & 150.7 & 282 \\
\hline Efficiency at Full Power & 0.57 & 0.57 \\
\hline Thrust-to-Power (mN/kW) & 41.9 & 63 \\
\hline Throughput (kg) & $>300^{*}$ & $>285^{*}$ \\
\hline Specific Mass (kg/kW) & 2.4 & 2.73 \\
\hline
\end{tabular}

\section{Throttling Options}

It has been observed that thruster erosion lifetime is not a linear function with power. ${ }^{4}$ The Dawn mission, the first NASA Discovery science mission with primary electric propulsion, has multiple thrusters that will operate one at a time. Additional thrusters are carried to achieve lifetime margin and redundancy requirements. There are also several missions of interest that require multiple thrusters operating concurrently. The terminology of consecutive thrusters refers to multi-thruster operation where a single thruster will be operated at full power before operating the second thruster. The terminology for concurrent operation refers to multiple thrusters operating where the two thrusters are throttled equally at all times. If the specific impulse and thruster efficiency do not significantly change at a throttled power level, it may be advantageous to operate two simultaneous thrusters at a lower (de-rated) power level. Operation in a de- 
rated condition to extend lifetime is a common technique used with electronic components that may be approaching lifetime limitations.
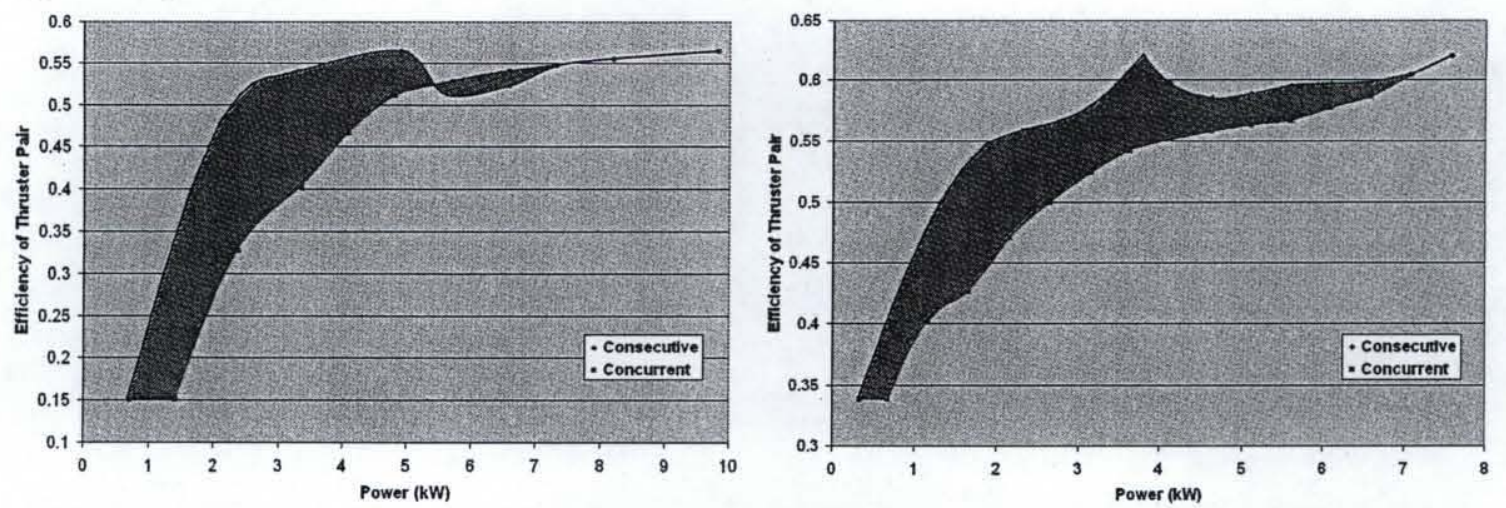

Figure 2: Thruster pair efficiency comparison for BPT-4000 (left) and HiVHAC (right) thrusters

Always operating thrusters in a throttled condition may not be practical for all missions and all thrusters. Some thrusters show a steep decline in performance at lower power. Also, thrusters that throttle with voltage are inherently throttling specific impulse with power. For example, the BPT-4000 can operate at specific impulses near $2000 \mathrm{~s}$ at both full and half power, while the HiVHAC thruster is designed to operate at a specific impulse at $2750 \mathrm{~s}$ near full power and at only $2100 \mathrm{~s}$ at half power. Figure 2 shows the efficiencies of a thruster pair operating either consecutively or concurrently. Figure 3 also illustrates how the specific impulse varies with power for the HiVHAC thruster. As the figure shows, specific impulse closely throttles with thruster efficiency. It is significantly more efficient to operate one thruster at full power than two at half power. If the lifetime margin is adequate, it would not be beneficial to operate at a lower specific impulse

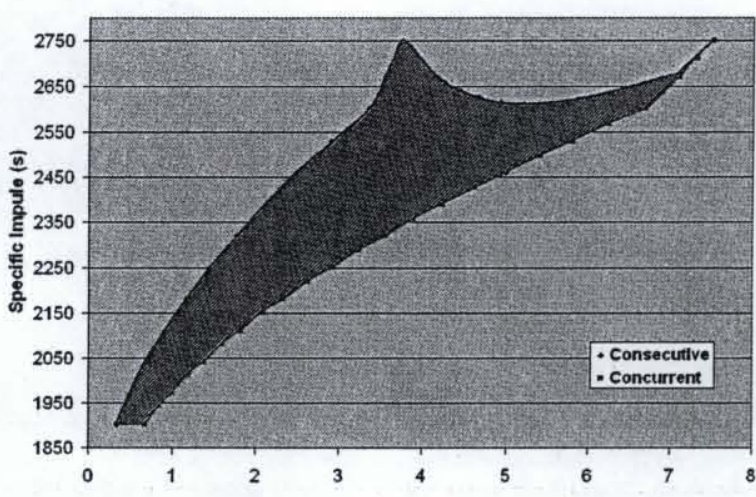

Figure 3: Specific impulses versus power for the HiVHAC thruster. than the thruster is designed.

\section{Results}

Results are calculated using the optimizer, SEPTOP ${ }^{5}$ or NEWSEP depending on the case, to determine the launch mass and propellant consumption. Standard propellant residuals and margins are used in addition to the propulsion system dry mass and propellant tankage fraction. The delivered mass listed in Table 2 provides the delivered spacecraft mass without the EPS wet mass. The results are compared in this fashion to adequately capture the propellant penalty and its effect of the overall system mass capability.

\section{A. Comet Rendezvous}

The Kopff comet rendezvous mission is presumed to be a discovery class mission for a small body rendezvous. Small body rendezvous missions are ideal for electric propulsion. Kopff is a Jupiter-family comet with an inclination of 4.7 degrees, a semi-major axis (sma) of $3.5 \mathrm{AU}$, an eccentricity of 0.54 and a period of 6.5 years. The consecutive throttling approach yields a higher delivered mass. Figure 4 illustrates the effect the throttling method has on performance. As expected, the performances approach one another as the Beginning of Life (B.O.L.) array power increases. As the array power increases, the amount of time spent operating at a lower efficiency throttled condition decreases. Table 2 provides specific details for one mission case. While the figure illustrates the overall mass capability, the table accurately accounts for the propellant mass, tankage fractions, reserves and residues, etc. Table 2 illustrates that using a consecutive throttling scheme will deliver approximately $50 \mathrm{~kg}$ of additional 
spacecraft and payload mass. For perspective, the total scientific payload of the Dawn mission is approximately $42 \mathrm{~kg} .^{6}$

Table 2: Kopff Comet Rendezvous Mission Characteristics for HiVHAC 9 kW Case.

\begin{tabular}{|l|c|c|}
\cline { 2 - 3 } \multicolumn{1}{c|}{} & Consecutive Throttling Mode & Concurrent Throttling Mode \\
\hline $\mathbf{\Delta V}(\mathrm{km} / \mathbf{s})$ & Delta II - 2925 & Delta II - 2925 \\
\hline Trip Time (Years) & 9.17 & 9.36 \\
\hline $\mathbf{C 3}\left(\mathrm{km}^{\mathbf{2}} / \mathbf{s}^{\mathbf{2}}\right)$ & 3.69 & 3.57 \\
\hline Power B.O.L. at 1 AU (kW) & 8.95 & 7.89 \\
\hline Launch Mass (kg) & 9.0 & 9.0 \\
\hline Propellant Mass (kg) & 1071.6 & 1095.6 \\
\hline Delivered Mass less EPS (kg) & 343.8 & 406.7 \\
\hline
\end{tabular}

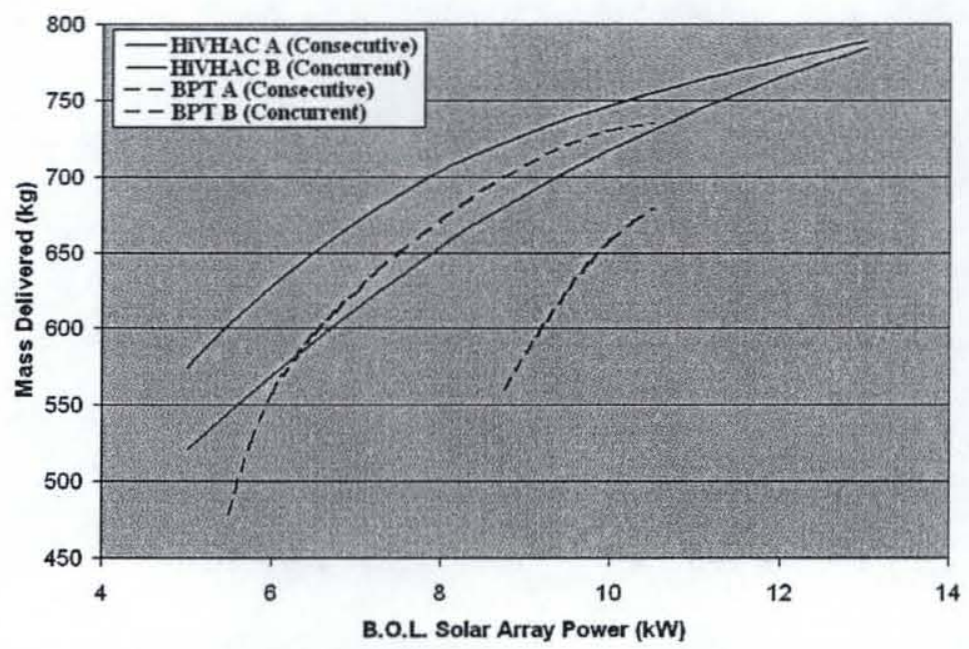

Figure 4: Comparison of consecutive and concurrent throttling for Kopff CR.

\section{B. Near Earth Object Sample Return}

The Near Earth Object (NEO) sample return mission is to the asteroid Nereus. Nereus is an Apollo and Mars-crosser asteroid. The asteroid is exceptionally accessible and has a rendezvous $\Delta \mathrm{V}$ lower that that of the moon. Of interest, Nereus was the original destination of the electric propulsion powered Hayabusa probe; however, a launch delay forced the Hayabusa mission to the asteroid Itokawa. Nereus has an inclination of 1.4 degrees, a semi-major axis of $1.5 \mathrm{AU}$, an eccentricity of 0.36 and a period of 663 days. A comparison of the effects of consecutive versus concurrent throttling methods on delivered mass capability is presented in Figure 5. The overall performance for this mission is not very sensitive to the throttling approach.

Table 3: Nereus Sample Return Mission Characteristics for HiVHAC 7 kW Case.

\begin{tabular}{|l|c|c|}
\cline { 2 - 3 } \multicolumn{1}{c|}{} & Consecutive Throttling Mode & Concurrent Throttling Mode \\
\hline Launch Vehicle & Delta II - 2925 & Delta II - 2925 \\
\hline $\mathbf{\Delta V}(\mathrm{km} / \mathbf{s})$ & 5.66 & 5.64 \\
\hline Trip Time (Years) & 3.56 & 3.56 \\
\hline $\mathbf{C} 3\left(\mathbf{k m}^{2} / \mathbf{s}^{2}\right)$ & 0.44 & 0.46 \\
\hline Power B.O.L. at 1 AU (kW) & 7.0 & 7.0 \\
\hline Launch Mass (kg) & 1281.2 & 1280.6 \\
\hline Propellant Mass (kg) & 247.7 & 253.3 \\
\hline Delivered Mass less EPS (kg) & $\mathbf{8 9 1 . 8}$ & $\mathbf{8 8 4 . 7}$ \\
\hline
\end{tabular}




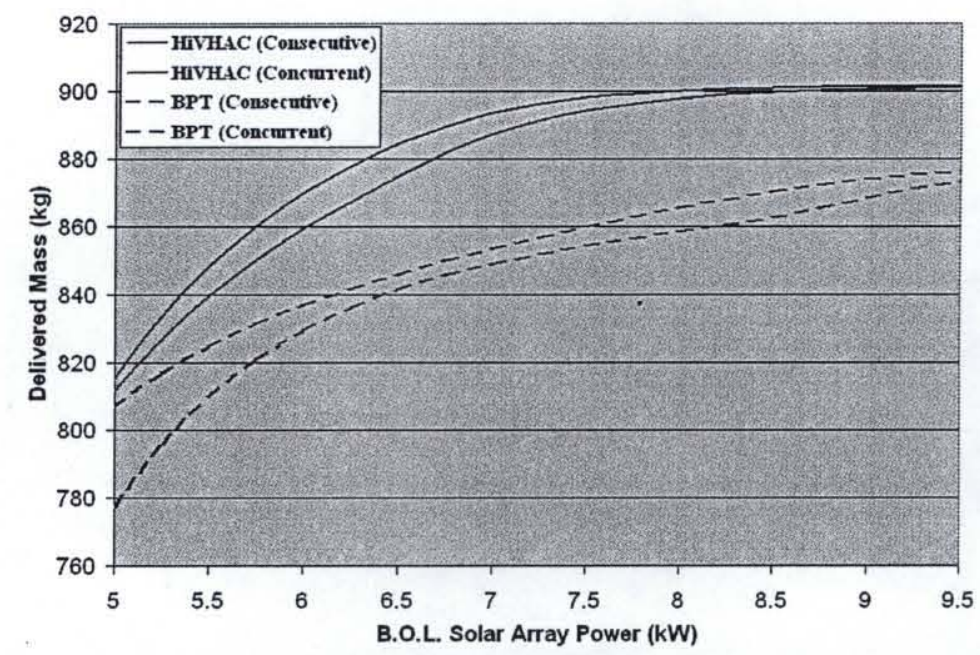

Figure 5: Comparison of consecutive and concurrent throttling for Nereus SR.

\section{Super-Dawn}

The Dawn mission is the first of its kind, in that it will stop at one destination, travel an extended distance, and then stop to study a second target. The potential for significant science return on multiple target missions is tremendous, yet limited by both how efficiently the spacecraft can travel between destinations and by the propulsion system lifetimes. The lifetimes of electric propulsion systems have increased significantly over NSTAR, with the advent of NEXT and new Hall systems, including the BPT-4000 and HiVHAC. Such thruster lifetime improvements offer the potential for a new class of missions. A "SuperDawn" class mission refers to traveling to and stopping at multiple high interest targets with a single launch. Unfortunately, most high interest targets are not necessarily co-located to allow for short transfers due to variances in inclination, eccentricity, period, etc., but sufficient throughput capability and creative mission planning could allow a single mission to visit multiple high interest targets and gain information at several secondary near-by targets. Potential targets for this "Super-Dawn" mission were chosen from a list of high interest targets formulated by the scientific community, and are listed in Table $4 .^{7}$

To evaluate a Super-Dawn mission (Table 4), the lifetime of a HiVHAC thruster was evaluated using a channel erosion model with a movable channel. In the HiVHAC thruster, the channel wall erodes until what would normally be considered a soft failure, and then the channel advances. For this analysis, the baseline HiVHAC design has a channel that can advance approximately $25 \mathrm{~mm}$, which allows the spacecraft to reach Nereus just prior to soft failure. The rate of erosion is predicted using a simplified erosion model based on the thruster power level and operating voltage for the specific leg of the mission. The mission example shown in Table 4 begins with an initial mass of $1650 \mathrm{~kg}$ launched towards Nereus on an escape trajectory. The remaining segments encompass departure and rendezvous with the next target. Limited effort was made to assure adequate phasing to complete the mission end-to-end.

\begin{tabular}{|c|c|c|c|c|c|c|c|c|c|}
\hline \multirow{7}{*}{ 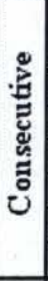 } & Segment & Target & Start Mass $(\mathbf{k g})$ & ISP (s) & $\begin{array}{c}\text { Average } \\
\text { Power (kW) }\end{array}$ & \begin{tabular}{|c} 
Remaining \\
Channel (mm)
\end{tabular} & $\Delta V(\mathrm{~km} / \mathrm{s})$ & $\begin{array}{c}\text { Propellant } \\
\text { required (kg) }\end{array}$ & End Mass (kg) \\
\hline & 1 & Nereus & 1650 & 2750 & & 25 & 5.6 & 309 & 1341 \\
\hline & 2 & $1993 \mathrm{BD} 3$ & 1341 & 2400 & 2.4 & 23.68 & 0.93 & 52 & 1289 \\
\hline & 3 & Belenus & 1289 & 2000 & 1.6 & 21.76 & 0.68 & 44 & 1245 \\
\hline & 4 & $1996 \mathrm{FG} 3$ & 1245 & 2500 & 2.8 & 1.84 & 11.2 & 456 & 789 \\
\hline & 5 & 1986 DA & 789 & 2700 & 3.6 & -12.19 & 13.9 & 322 & 467 \\
\hline & 6 & Apophis & 467 & 2550 & 5.2 & -17.2 & 15.35 & 214 & 253 \\
\hline \multirow{7}{*}{$\dot{0}$} & Segment & Target & Start Mass $(\mathrm{kg})$ & ISP (s) & $\begin{array}{c}\text { Average } \\
\text { Power (kW) }\end{array}$ & $\begin{array}{c}\text { Remaining } \\
\text { Channel (mm) }\end{array}$ & $\Delta V(\mathbf{k m} / \mathrm{s})$ & $\begin{array}{c}\text { Propellant } \\
\text { required (kg) }\end{array}$ & End Mass (kg) \\
\hline & $\frac{1}{1}$ & Nereus & 1650 & 2750 & & 25 & 5.6 & 310 & 1340 \\
\hline & 2 & $1993 \mathrm{BD} 3$ & 1340 & 1800 & 2.4 & 24.45 & 0.93 & 69 & 1271 \\
\hline & 3 & Belenus & 1271 & 1500 & 1.6 & 23.17 & 0.68 & 57 & 1214 \\
\hline & 4 & 1996 FG3 & 1214 & 1900 & 2.8 & 11.13 & 11.2 & 549 & 665 \\
\hline & 5 & $1986 \mathrm{DA}$ & 665 & 2150 & 3.6 & 3.92 & 13.9 & 321 & 344 \\
\hline & 6 & Apophis & 344 & 2450 & 5.2 & 0.31 & 15.35 & 163 & 181 \\
\hline
\end{tabular}


The results from table 4 provide an example of what advantage their may be to operating thrusters in a de-rated mode by throttling them concurrently; fewer required thrusters. In this hypothetical "SuperDawn" mission, the consecutive throttling example operates at higher efficiency and higher specific impulse, but also at higher erosion rates. The consecutive throttling example thus requires another thruster pair to complete the mission's lifetime requirements. The concurrent throttling example is able to complete the mission with a single thruster pair. However, the consecutive throttling example can complete the mission with approximately $70 \mathrm{~kg}$ less propellant. Because the dry mass of an additional thruster string is approximately $30 \mathrm{~kg}$ (40 kg with appropriate contingency), the performance of the two options are relatively close. The cost and complexity reduction from requiring fewer thrusters could be significant.

\section{Comet Surface Sample Return}

The Comet Surface Sample Return (CSSR) mission is a challenging mission for existing propulsion systems, and has been studied as a representative New Frontiers class electric propulsion design reference mission. The characteristics of the CSSR missions include a direct trajectory to the comet, a surface stay time of sixty days, and then a direct return to Earth. One of the propulsion challenges of a CSSR mission is meeting entry velocity requirements at Earth. Based on previous missions and analyses, the maximum entry velocity of the return capsule is assumed to be $13 \mathrm{~km} / \mathrm{s}$. For this study, the comet Wirtenan was chosen as the target. The mission was performed using two HiVHAC thrusters and ten kilowatts of spacecraft power at one A.U. Additional mission specifications are provided in Table 5.

Table 5: Comet Wirtenan Sample Return Mission Characteristics

\begin{tabular}{|l|c|c|}
\cline { 2 - 3 } \multicolumn{1}{c|}{} & Consecutive Throttling Mode & Concurrent Throttling Mode \\
\hline Launch Vehicle & Atlas 401 & Atlas 401 \\
\hline $\boldsymbol{\Delta V}(\mathrm{km} / \mathbf{s})$ & 12.2 & 13.9 \\
\hline Trip Time (Years) & 8.1 & 8.1 \\
\hline $\mathbf{C 3}\left(\mathrm{km}^{2} / \mathbf{s}^{2}\right)$ & 34.2 & 32.1 \\
\hline Power B.O.L. at 1 AU (kW) & 10 & 10 \\
\hline Launch Mass $(\mathbf{k g})$ & 1683.7 & 1772.3 \\
\hline Propellant Mass $(\mathrm{kg})$ & $\mathbf{7 2 4 . 5}$ & 935.6 \\
\hline Delivered Mass less EPS (kg) & $\mathbf{7 4 6 . 2}$ & $\mathbf{5 9 2 . 1}$ \\
\hline
\end{tabular}

Table 6 provides the duration spent at each of the thrusters throttle points. NEWSEP was used as the trajectory optimization tool. Although electric propulsion thrusters can operate at over 100 throttle points in the model, for this analysis the thruster was assumed to operate at the 13 step functions shown below. Table 6 illustrates the operational time for two thrusters throttled either consecutively or concurrently. The top line in the PPU input power, ranging from 335 Watts to $3.758 \mathrm{kWe}$, and the numbers below represent the number of hours operated at that specific throttle condition in hours and then as a percentage of the total thruster operating time. As expected, the concurrent throttling case operated at the lowest power level and erosion rate for more than $50 \%$ of the total operating time. It is important to note that the consecutive throttling scenario operated at less than $50 \%$ power over $60 \%$ of the time without artificially operating at lower power levels. The consecutive throttling case operates at full power for $60 \%$ longer than the concurrent case. The increase in duration with a corresponding increase in erosion rate could require an additional thruster to provide sufficient life beyond that required of the concurrent throttling case; however, the consecutive throttling case uses $20 \%$ less propellant throughput and can deliver $20 \%$ more spacecraft mass. For this specific case, this means that the consecutive throttling case can actually carry four additional thrusters purely to meet lifetime needs and still outperform the concurrent throttling scheme.

Table 6: Thrusters combined operational time at each throttle point in hours.

\begin{tabular}{|c|c|c|c|c|c|c|c|c|c|c|c|}
\hline \multirow{3}{*}{ Consecutive } & $\mathbf{0}$ & 0.335 & 0.824 & 1.313 & 1.802 & 2.291 & 2.78 & 3.269 & 3.758 & Total & Per Thruster \\
\hline & 79560 & 17328 & 14496 & 6072 & 3912 & 2904 & 2304 & 1944 & 13248 & 62232 & 31128 \\
\hline & $\mathrm{NA}$ & $27.9 \%$ & $23.3 \%$ & $9.8 \%$ & $6.3 \%$ & $4.7 \%$ & $3.7 \%$ & $3.1 \%$ & $21.3 \%$ & & \\
\hline \multirow[t]{2}{*}{ Concurrent } & 43872 & 51888 & 16920 & 7968 & 5184 & 3552 & 2448 & 2208 & 8088 & 98232 & 49128 \\
\hline & NA & $52.8 \%$ & $17.2 \%$ & $8.1 \%$ & $5.3 \%$ & $3.6 \%$ & $2.5 \%$ & $2.2 \%$ & $8.2 \%$ & & \\
\hline
\end{tabular}


The overall results of the various cases (Kopff CR, Nereus SR, and CSSR) are shown in Figure 6. In general the concurrent thruster throttling shows somewhat lower performance compared to the consecutive throttling method. As expected, the performance penalty is more significant for higher $\Delta \mathrm{V}$ missions. While cost has not been considered, it appears that the highest performance can be achieved by carrying a spare thruster for life, and always operating the thrusters consecutively at their highest designed input power.

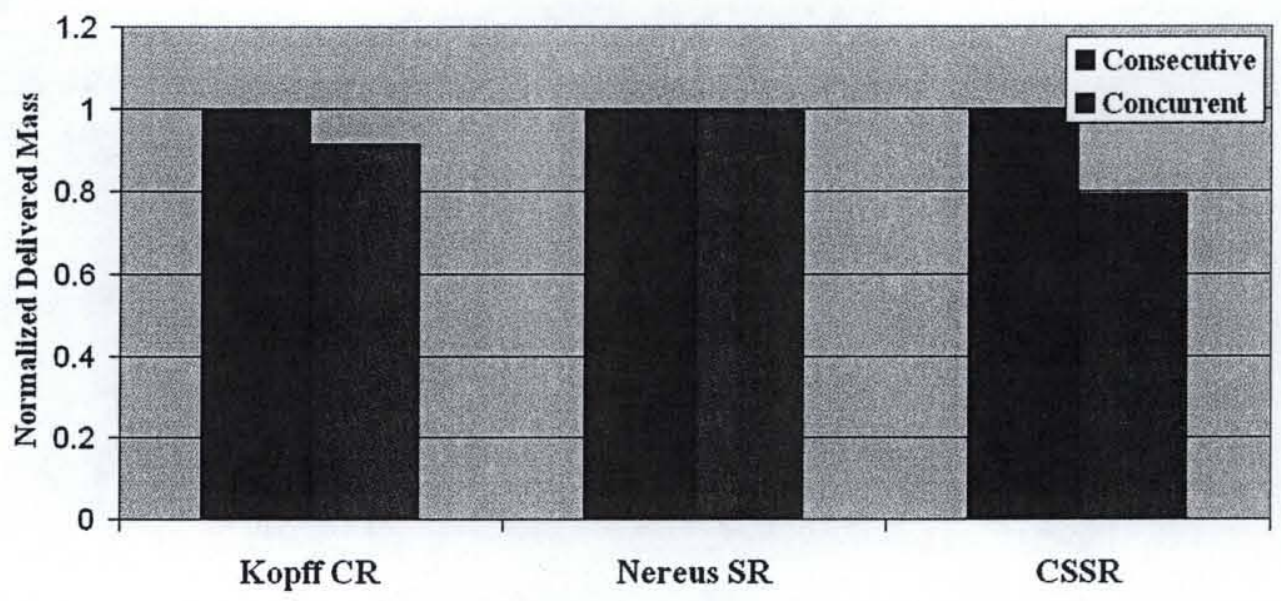

Figure 6: Normalized comparison of delivered mass for the three missions.

\section{De-rated Thruster Operation}

There are several missions that could be completed with a single thruster by operating the thruster at lower power to increase the expected lifetime. Because thruster operation at full power has the highest erosion rate, operational life can be increased by operating the thruster in a de-rated mode, below its designed maximum power. De-rating electronic components to achieve life goals is a standard industry practice; however, unlike electronics, the thruster efficiency is also a maximum at the full power design throttle condition. As such, while thruster lifetime will increase, thruster performance is expected to decrease during operating in de-rated mode. The performance effects of de-rating three HiVHAC thrusters for the Kopff comet rendezvous and Nereus sample return missions are shown in Figure 7. Table 7 compares the delivered spacecraft and payload mass (after removing the EPS wet mass) for three de-rated HiVHAC thrusters versus two full power HiVHAC thrusters and one spare. The table shows that the performance decrease when using the de-rated system roughly balances the mass penalty of carrying an additional thruster string operated at full thruster power, and delivers approximately the same net mass to the target destination.
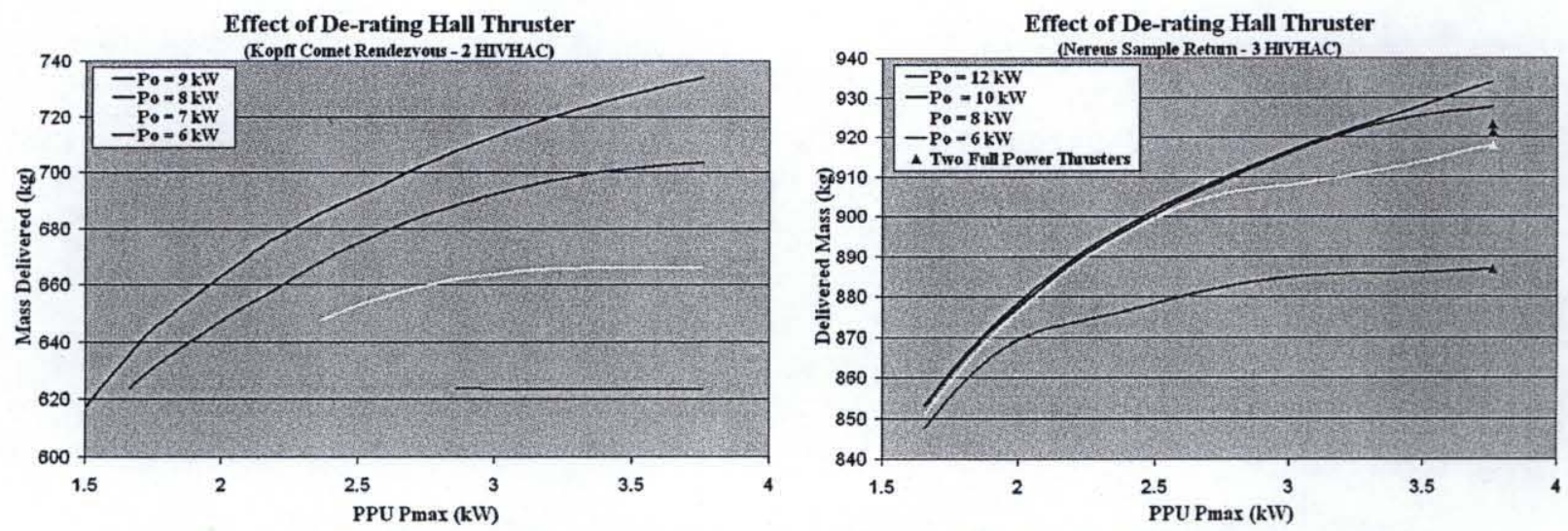

Figure 7: Thruster de-rating impact on performance for Kopff CR and Nereus SR. 
The performance effect due to de-rating the thruster is largely dependent on the solar array power (Po). Having a higher initial solar array power will provide an opportunity to run the thrusters at maximum power for the greatest amount of time. As such, performance changes may not be significantly limited due to a change in de-rated thruster efficiency, but rather because the de-rating of the thruster limits the amount of power that can be used. In general, a system that can efficiently use all of the available power will have the highest performance. For both missions, the de-rating effect becomes more significant as the array power increases. The Nereus mission also illustrates that for higher power missions, it may be more beneficial to carry a spare thruster for life rather than de-rating the operational thruster; cost not included.

Table 7: Nereus Sample Return Mission De-rated Comparison.

\begin{tabular}{|l|c|c|}
\cline { 2 - 3 } \multicolumn{1}{c|}{} & Three De-rated Thrusters & Two Full Power + Life Spare \\
\hline Launch Vehicle & Delta II - 2925 & Delta II - 2925 \\
\hline $\mathbf{\Delta V}(\mathbf{k m} / \mathbf{s})$ & 4.45 & 4.60 \\
\hline Trip Time (Years) & 3.11 & 3.12 \\
\hline C3 $\left(\mathbf{k m}^{2} / \mathbf{s}^{2}\right)$ & 1.10 & 1.40 \\
\hline Power B.O.L. at 1 AU (kW) & 12.0 & 12.0 \\
\hline Launch Mass (kg) & 1263.4 & 1255.4 \\
\hline Propellant Mass (kg) & 189.6 & 193.9 \\
\hline Net Mass Capability (kg) & $\mathbf{9 0 7 . 6}$ & $\mathbf{8 9 4 . 6}$ \\
\hline
\end{tabular}

The converse to de-rated operation is the possibility of operating a thruster beyond its nominal condition. Because mission performance is strongly dependent on the maximum operating power of the thruster, there are scenarios that may warrant operating a thruster above its nominal maximum input power. The Xenon Ion Propulsion System (XIPS) thruster is an example where the thruster operates at approximately $2 \mathrm{kWe}$ at plasma densities near that of the NSTAR thruster during low-power station keeping operation. The XIPS, however; also operates at full $(4.2 \mathrm{kWe})$ power for short duration during orbit topping maneuvers. The erosion rates of the grids are much higher at full power, but because the duration of full power operation is sufficiently short, the thruster can still meet its mission objectives.

\section{Thruster Lifetime Qualification}

The qualification of electric propulsion thrusters is a major expense and challenge to rapid infusion of new technology. The qualification of space hardware has strict lifetime objectives that must be met prior to flying any piece of flight hardware. Current electric propulsion thruster lifetime qualification standards are based on historical (primarily chemical propulsion) qualification procedures that may unnecessarily increase the time and cost required to qualify new thruster technology. Of even more concern, following the standard qualification procedures may not adequately validate the life of the thruster in all phases of mission operations.

While the actual safety factor differs slightly from ESA, NASA, DoD, and commercial applications, the standard practice is to validate new thruster technology with a lifetime demonstration some fraction beyond the expected operational life of the thruster. For NASA requirements, thruster life must be demonstrated at $150 \%$ of expected mission thruster operational life. For commercial applications, lifetime validation through demonstration may be costly but is still feasible for most applications because commercial applications typically require total electric propulsion system operating times of a few hundred to a few thousand hours. In addition, commercial applications tend to operate at only a few operating points, near the full power operating condition. For example, the BPT-4000 thruster was designed with four primary operating points; two power levels at two different voltage. The first mode, orbit topping, assumes a maximum duration of 100 days for all missions. The qualification test successfully demonstrated over 2,400 hours at this high current condition. The second mode of operation, station keeping and other lower power operating conditions, was also tested for another 3,000 hours. ${ }^{8}$ The total demonstration time required for the BPT- 4000 was thus still under 6000 hours, and while costly, still feasible to complete by direct ground test. While the BPT- 4000 has the highest throughout capability of any qualified thruster, electric thrusters with significant increases in throughput capability are already under development. Eventually, industry will face more difficult qualification by test challenges as more ambitious commercial missions leverage advanced electric propulsion system for larger $\Delta \mathrm{V}$ maneuvers. 
During the short life of the Prometheus nuclear electric propulsion (NEP) program, lifetime qualification was considerably less rigorous in terms of demonstration requirements. It was understood that the NEP thrusters would need to operate for so long that the lifetime ground demonstration would still be occurring well after the mission was scheduled to launch. For NEP applications, it was given that lifetime qualification must occur through a combination of ground test and analyses because a full operational life demonstration could not be achieved.

Even solar electric propulsion (SEP) mission life requirements may exceed the time available for ground testing. Figure 8 illustrates the thruster throttling that can be expected from a CSSR SEP mission. The mission begins at high power, two full power thrusters, but quickly drops to a single thruster operating at a de-rated condition for a large percentage of the mission. As was shown in Table 6, the majority of the mission occurs at low power, but clearly throttles the full range of allowable power. Even if the mission was known a priori, it would be impractical to life test as flown.

Thruster Power vs. Mission Time

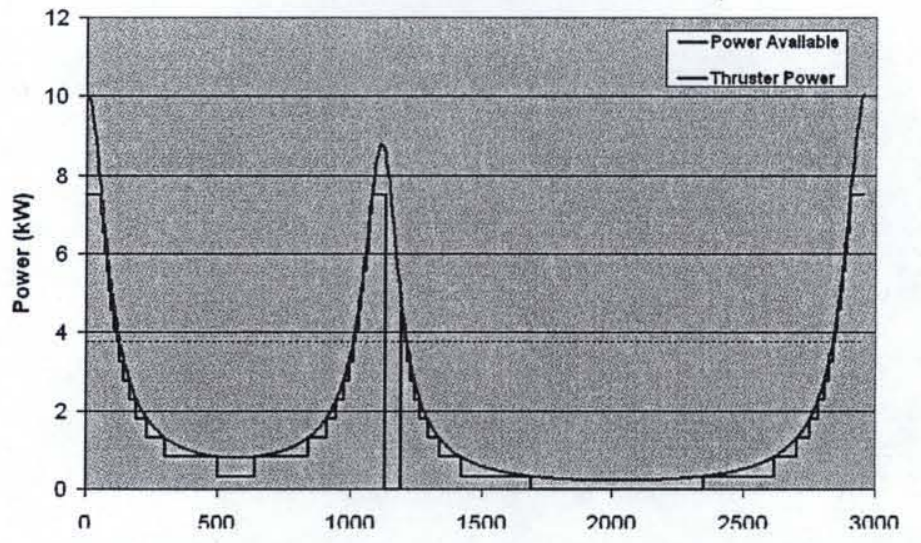

Figure 8: Solar array and thruster power profile for CSSR mission.

When a new thruster technology does not have a set mission launch date, a full lifetime demonstration may be possible but could still be impractical and costly. Current NASA operational requirements still call for a $150 \%$ throughput (lifetime) demonstration. Using just total propellant throughput as the demonstration criterion, a program would benefit by operating the thruster at full power for as long as possible in order to demonstrate the total throughput in the shortest amount of time. For example, the NEXT demonstration of $450 \mathrm{~kg}$ of throughput requires over than 20,000 hours of operation at full power, or 35,000 hours if total throughput is validated using a nominal throttle table. While saving time and lowering costs, operating at full power may not provide the necessary lifetime validation data, may not adequately stress the hardware, and certainly does not represent expected mission operation.

NASA's handbook for systems engineering clearly states that test is the preferred method of qualification for new hardware. However, it goes on to state that "Analysis may be used when it can be determined that rigorous and accurate analysis is possible, testing is not feasible or cost-effective, similarity is not applicable, or verification by inspection is not adequate." ${ }^{9}$ Analytical tools have been created by NASA and are recognized by virtue of use on prior programs. Stress, fracture, thermal, ionizing radiation, mass properties and power, and energy requirements are examples of qualification requirements met by analysis rather than test on previous programs.

As an example of the inadequacy of full power testing for electric propulsion missions, representative erosion analysis was conducted to estimate thruster life at various power levels for a comet rendezvous mission. The erosion rates are based on the preliminary results from the University of Michigan numerical simulation

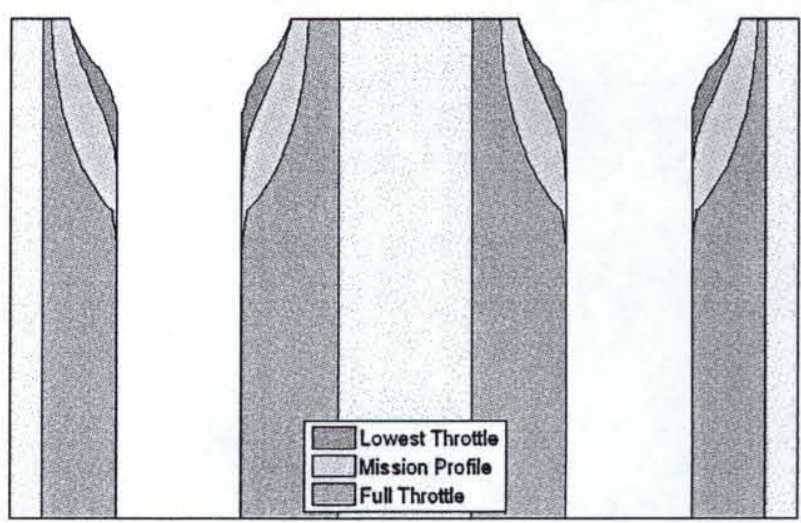

Figure 9: Example end of mission erosion profiles. 
developed for the HiVHAC program..$^{10,11,12}$ As shown in Figure 9, the thruster erosion and hence life can vary significantly based on the thruster operating conditions. The erosion model predicts an erosion rate than practically goes to zero at low power / low voltage operation. The erosion profile also displays significant variation based on the threshold voltage and magnetic topology. While Figure 9 is just for illustration, it does clearly show that full power life testing does not accurately characterize the mission profile operation. Full power qualification testing may also neglect wear mechanisms only observed at lower powers. ${ }^{13}$ If full life qualification at representative operating conditions is not possible due to time or cost constraints, then qualification by a combination of test and analyses appears critical to fully understand the wear mechanisms.

Figure 9 also illustrates an additional challenge in demonstrating the required $150 \%$ life margin; how is the margin applied. Currently, the metric used for margin is propellant throughput capability. Figure 9 displays the erosion profile created for a comet rendezvous mission that requires almost $300 \mathrm{~kg}$ of propellant throughput. The thruster does not have 50\% margin in propellant throughput at full power, but it would have significant margin if the remaining propellant margin can be achieved at low power. The example thruster is designed to fail near $300 \mathrm{~kg}$ of full power operation; however, there are several missions than can be completed requiring greater than $300 \mathrm{~kg}$ of propellant throughput and still show adequate margin if the majority of the mission was run at low power. It is easy for a technical reviewer unfamiliar with the technology to assume full power operation is the most stressing condition and therefore the thruster must demonstrate $50 \%$ margin at the most stressing condition. Not only is that an incorrect assumption, but it will unnecessarily limit the use of electric propulsion. A new standard metric should be developed and accepted by technology providers and users. An example of such a standard might be $50 \%$ margin in operational time at each throttle condition as seen during the mission. Once the standards are determined, it is recommended that the actual erosion mechanisms be fully characterized over the full range of operation, and then margin can be justified by analyses after the mission requirements are known.

\section{Gridded Ion Thrusters}

While the intent of this paper has been to focus on Hall thrusters, gridded ion engines may be better suited to take advantage of de-rated operation schemes, but the erosion analysis should be conducted with an ion optics erosion tool. Gridded ion engines are already operated in a de-rated mode. As mentioned earlier, the XIPS thruster operates at full power only for a short duration during orbit topping and then operates at approximately $50 \%$ power for the majority of its operational lifetime. At $50 \%$ power the XIPS has current densities close to that of the NSTAR thruster. Though the PPU is not designed for higher power operation, the NEXT thruster has been tested up to $13.6 \mathrm{~kW} .{ }^{14}$ By operating at a lower power level, the lifetime, and in most cases, the total impulse capability of the thruster is significantly increased.

Because of the performance curve of the NEXT thruster, it may provide some increases in life without a decrease in performance. Figure 10 illustrates that the efficiency of the thruster peaks near $4 \mathrm{~kW}$ and levels off. Though the analysis has not yet been performed, it appears beneficial to operate the thruster at high power, limited only by the PPU and available solar array power. Also, it appears that few missions with multiple NEXT thrusters operating over the baseline throttle table will ever encounter an erosion limitation.

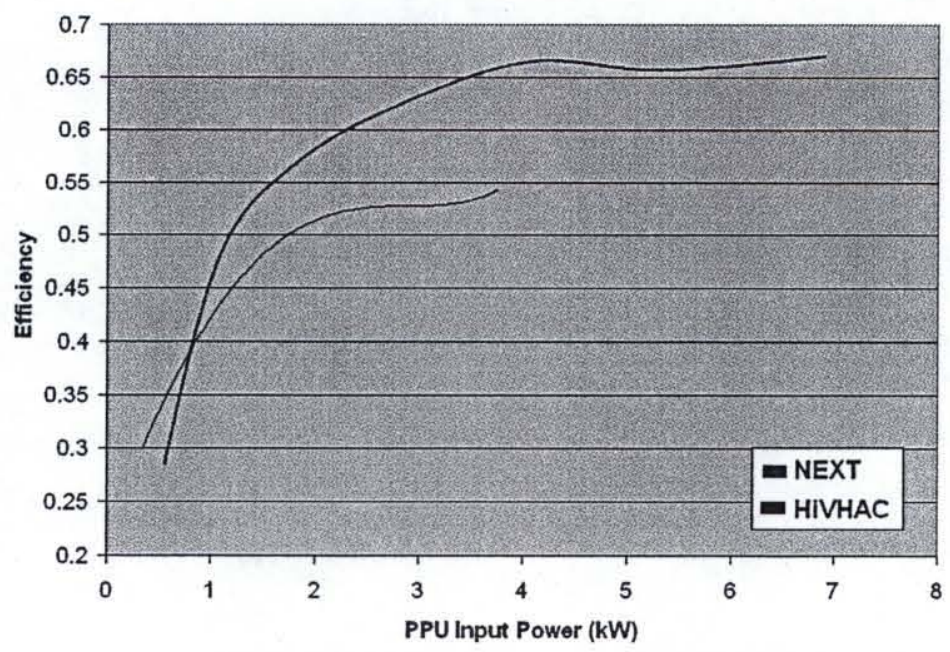

Figure 10: NEXT and HiVHAC performance curves. 


\section{Conclusions and Recommendations}

The primary trends observed from these analyses include:

1. For Hall thrusters that throttle in specific impulse and efficiency with power, the thrusters have better performance when operated consecutively rather than throttled concurrently.

2. Operation of Hall thrusters in a de-rated mode significantly decrease the mission performance, and in some cases carrying an additional thruster to meet lifetime objectives can still deliver more mass than operating the thruster in a de-rated mode to maximize a thruster's life.

3. Full power qualification by test does not adequately predict thruster life as it will be flown.

4. Qualification by analysis is critical to the infusion of new EP technology.

5. Erosion mechanisms should be characterized and validated through test over a thruster's operating range, and then lifetime projections should be predicted based on actual mission profiles.

6. Modular PPUs may provide a method to allow for the greatest mission capture and performance if lifetime qualification by analyses is sufficient.

\section{Acknowledgements}

The work described in this paper was funded in whole or in part by the In-Space Propulsion Technologies Program, which is managed by NASA's Science Mission Directorate in Washington, D.C., and implemented by the In-Space Propulsion Technology Projects Office at Marshall Space Flight Center in Huntsville, AL during the period of performance. The program objective is to develop in-space propulsion technologies that can enable or benefit near and mid-term NASA space science missions by significantly reducing cost, mass and travel times.

\section{References}

${ }^{1}$ De Grys, K., et al., "BPT-4000 Multi-Mode 4.5 kW Hall Thruster Qualification Status," AIAA-20034552, Huntsville, AL, July 2003.

${ }^{2}$ Hofer, R. R., Randolph, T. M., Oh, D. Y., Snyder, J. S., and De Grys, K. H., "Evaluation of a 4.5 kW Commercial Hall Thruster System for NASA Science Missions," $42^{\text {nd }}$ AIAA/ASME/SAE/ASEE Joint Propulsion Conference, AIAA 2006-4469, July 2006.

${ }^{3}$ Welander, B., "Qualification Test Report - General Release Hall Thruster Propulsion System BPT4000 Hall Cureent Thruster," Aerojet Test Report 2006-R-2791, October 2006.

${ }^{4}$ Van Noord, J., "NASA's Evolutionary Xenon Thruster (NEXT) Ion Propulsion System - Technology for NASA Space Science Missions - Service Life Assessment," GRC-NEXT-103, December 21, 2005.

${ }^{5}$ Sauer, Carl G., Jr., "General Purpose Low-thrust Trajectory Optimization Programs," JPL User's Guide to VARITOP, SAIL, and SEPTOP, February 2002.

${ }^{6}$ Rayman, M. D., Fraschetti, T. C., Raymond, C. A., and Russell, C. T., "Dawn: A Mission in Development for Exploration of Main Belt Asteroids Vesta and Ceres," $55^{\text {th }}$ International Astronautical Congress, IAC-04-Q.5.05, October 2004.

${ }^{7}$ Mitchell, S., "Analysis and Identification of Three-Asteroid (NEO) Rendezvous Missions," $15^{\text {th }}$ AAS/AIAA Space Flight Mechanics Conference, AAS 05-142, January 2005.

${ }^{8}$ Williams, J. D., "Solar Electric Propulsion Technology Assessment Group Final Report," NASA MSFC ISPT SEP-06-101, February 2006.

${ }^{9}$ Satern Training program (or system's analysis handbook)

${ }^{10}$ Manzella, D., Yim, J., and Boyd, I., "Predicting Hall Thruster Operational Lifetime," $40^{\text {th }}$ AIAA/ASME/SAE/ASEE Joint Propulsion Conference, AIAA-2004-3953, July 2004.

${ }^{11}$ Yim, J. T., Keidar, M., and Boyd I. D., "An Evaluation of Sources of Erosion in Hall Thrusters," $41^{\text {st }}$ AIAA/ASME/SAE/ASEE Joint Propulsion Conference, AIAA 2005-3530, July 2005.

${ }^{12}$ Yim, J. T., Keidar, M., and Boyd I. D., "An Investigation of Factors Involved in Hall Thruster Wall Erosion Modeling," 42 ${ }^{\text {nd }}$ AIAA/ASME/SAE/ASEE Joint Propulsion Conference, AIAA 2006-4657, July 2006.

${ }^{13}$ Sengupta, A., Brophy, J. R., Anderson, J. R., Garner, C., de Groh, K. et al., "An Overview of the Results from the 30,000 Hr Life Test of Deep Space 1 Flight Spare Ion Engine," AIAA Paper 2004-3608, July 2004.

${ }^{14}$ Patterson, M. J., "NEXT Study of Thruster Extended-Performance (NEXT STEP)," $42^{\text {nd }}$ AIAA/ASME/SAE/ASEE Joint Propulsion Conference, AIAA 2006-4664, July 2006. 